\title{
Advanced High Strength Steel in Auto Industry: an Overview
}

\author{
Nazim Baluch \\ School of Technology Management \\ \& Logistics \\ COB, Universiti Utara Malaysia \\ nazimbaluch@uum.edu.my
}

\author{
Zulkifli Mohamed Udin \\ School of Technology Management \\ \& Logistics \\ COB, Universiti Utara Malaysia \\ zulkifli@uum.edu.my
}

\author{
Che Sobry Abdullah \\ School of Technology Management \\ \& Logistics \\ COB, Universiti Utara Malaysia \\ sobry@uum.edu.my
}

\begin{abstract}
The world's most common alloy, steel, is the material of choice when it comes to making products as diverse as oil rigs to cars and planes to skyscrapers, simply because of its functionality, adaptability, machine-ability and strength. Newly developed grades of Advanced High Strength Steel (AHSS) significantly outperform competing materials for current and future automotive applications. This is a direct result of steel's performance flexibility, as well as of its many benefits including low cost, weight reduction capability, safety attributes, reduced greenhouse gas emissions and superior recyclability. To improve crash worthiness and fuel economy, the automotive industry is, increasingly, using AHSS. Today, and in the future, automotive manufacturers must reduce the overall weight of their cars. The most cost-efficient way to do this is with AHSS. However, there are several parameters that decide which of the AHSS types to be used; the most important parameters are derived from the geometrical form of the component and the selection of forming and blanking methods. This paper describes the different types of AHSS, highlights their advantages for use in auto metal stampings, and discusses about the new challenges faced by stampers, particularly those serving the automotive industry.
\end{abstract}

Keywords: advanced high strength steel; automotive industry; auto metal stampings; AHSS

\section{INTRODUCTION}

Steel powerfully impacts how all seven billion of us on the planet go about our daily lives, wherever we are. Touching every aspect of the way we live, work and play; no other material provides the same unique combination of strength, formability and versatility. Steel helps feed and clothe us, provides employment and makes infrastructure, construction and transportation possible; and all this is done sustainably with a recycling rate well above 90 percent. The world's most common alloy, steel, is the material of choice when it comes to making products as diverse as oil rigs to cars, planes to skyscrapers simply because of its functionality, adaptability, machine-ability and strength [1]. To improve crash worthiness and fuel economy, the automotive industry is, increasingly, using Advanced High Strength Steel (AHSS). Manufacturers unavoidably have to reduce the overall weight of automotives. The most cost-efficient way to do this is with AHSS.

However, there are several parameters that decide which AHSS type to be used. The most important parameters derive from the selection of forming and blanking methods and from the geometrical form of the component [2]. Using AHSS offers many environmental advantages. When weight is reduced, a smaller amount of raw material is used and less energy is consumed. At the same time, less energy is needed to transport the steel [2].

\section{AHSS EXPOSITION}

The term AHSS is generally used for dual phase steels, complex phase steels, TRIP steels and martensitic steels. It primarily stands for multi-phase steels. The high yield strength micro-alloyed steels also belong to the AHSS group. Conventional high strength steels are single phase ferritic steels. Automotive steels are classified in three designations: metallurgical designation includes low-strength steels, conventional high strength steel, and the newer types of AHSS. The second classification method, important to part designers, is the strength of the steel. The third classification method presents various mechanical properties or forming parameters of different steels, such as total elongation, work hardening exponent $\mathrm{n}$, or hole expansion ratio.

The metallurgy and processing of AHSS grades are somewhat novel compared to conventional steels. Their remarkable mechanical properties is the result of their unique processing and structure. All AHSS are produced by controlling the cooling rate from the austenite or austenite plus ferrite phase, either on the run-out table of the hot mill (for hotrolled products) or in the cooling section of the continuous annealing furnace (continuously annealed or hot-dip coated products). They are classified into six categories: Dual Phase (DP) steel, Transformation-Induced Plasticity (TRIP) steel, Complex Phase (CP) steel, Martensitic (MS) steel, FerriticBainitic (FB) steel and Twinning-Induced Plasticity (TWIP) steel.

The AHSS solve two distinct automotive needs by two different groups of steels. The first group, as a class, has higher strength levels with improved formability and crash-energy absorption compared to the current HSLA (High Strength Low Alloy) grades. This requirement is fulfilled by the DP and TRIP grades of steel, which have increased values of the work hardening exponent. The second is to extend the availability of steel in strength ranges above the HSLA grades. This area is covered by the CP and MS grades. Originally targeted only for chassis, suspension, and body-in-white components, AHSS are 
now being applied to doors and other body panels. Additional steels are designed to meet specific process requirements. These include increased edge stretch flange-ability, strengthening after forming, or increased springback tolerances.

By combining a number of different microstructures not traditionally found in conventional HSS, a wide range of properties are possible with AHSS. This allows steel companies to tailor the processing to meet the ever more focused application requirements demanded by the automotive industry.

\section{A. Evolving AHSS types}

In response to automotive demands for additional AHSS capabilities, steel industry research continues to develop new types of steel [3]. These steels are designed to reduce density, improve strength, and/or increase elongation. For example, nano steels are designed to avoid the low values of edge stretch (local elongation) experienced by DP and TRIP steels. Instead of islands of martensite, the ferrite matrix is strengthened with ultra-fine nano-sized $(<10 \mathrm{Nm})$ particles. This is accomplished in hot-rolled high strength steel with a tensile strength around $750 \mathrm{MPa}$. The resulting steel has a high YS/TS ratio with an excellent balance of total elongation and local elongation (hole expansion ratio). Other examples of these developing steels are ultrafine grain, low density, and high Young's modulus steels [3].

\section{B. AHSS benefits}

AHSS is most advantageous when used for safety components, structural parts of the car body and the chassis. As a general rule, the weight reduction is about 50 percent, i.e. when compared to mild steel the thickness is halved without sacrificing strength. As a result, AHSS has become the material of choice for sill reinforcements, A-pillars, B-pillars, side impact beams, waistline reinforcements, bumpers, roof bows and seats. AHSS steel has also been introduced in all other vital areas of the car and many new cars are already composed of 30 to 40 percent AHSS. In only a few years, AHSS is predicted to make up 40 to 50 percent of the sheet steel used in cars contributing to a 5 percent reduction in total GHG (Green House Gas) emissions. The advantages of using AHSS are evident in all types of cars. Small cars benefit from greatly improved crash safety while heavier cars, like SUVs, can be made much more fuel efficient.

The smooth and cost-efficient transition from mild steels, or conventional high strength steels, to AHSS is one of the factors behind the success of AHSS within the automotive industry. This is because AHSS can be formed and joined in much the same way as milder steel, but with only half the thickness. The cutting and forming of AHSS can be done without increased force and common welding and joining techniques can be used with only minor adjustments.

Even greater benefits can be gained when switching to new forming methods, like roll forming. This process enables the manufacturer to produce complicated profiles in a single run; roll forming can be done with lower tool wear and very tight radii of the profile when using AHSS. The advantages of
AHSS over aluminum are easily summarized: lower cost with the same weight and strength. The ability to form complicated profiles is another of the many benefits offered by AHSS compared to aluminum. On beams inside the car, aluminum must be three times the thickness of AHSS to provide the same strength. When compared with new materials, such as composites, the cost benefits of using AHSS is even more apparent. The automotive industry of today has decided that AHSS is superior to aluminum for nearly all applications.

\section{Designing with AHSS}

From a design point of view, AHSS is generally a favored solution. However, the high stresses and low thickness puts emphasis on finding a solution that uses the full potential of the material. Design challenges can include local buckling effects, loss in stiffness, robustness and fatigue issues. With the right production process and design, it is easy to deal with these challenges.

\section{The strengths of AHSS}

Dual phase and martensitic steels are available with very high initial yield strength. In addition to this initial strength, they also exhibit a pronounced work-hardening when formed, as well as a bake hardening effect from the painting process. Typically the work-hardening effect is about $150 \mathrm{MPa}$ at a strain of two percent and the corresponding bake hardening effect another $50 \mathrm{MPa}$ for a typical painting process.

In addition to the work and bake hardening effect, AHSS exhibits a strain rate hardening effect, i.e. they sustain higher stresses at an increased deformation speed. This effect corresponds to an increase of about $100 \mathrm{MPa}$ for the high strain rates that are involved locally in a car crash. The high strength of AHSS is a useful tool to reduce the weight of the body-inwhite (BIW), bumpers systems, door side impact beams, seat structures etc.

\section{E. Optimizing the energy absorption}

There is a potential to reduce the weight in components, by upgrading the strength of the steel. Generally the absorbed energy is proportional to the square of the thickness and linear to the tensile strength of the material. If for instance the tensile strength of the steel is doubled, the thickness and the weight can be reduced by 30 percent, resulting in equivalent energy absorption. One of the main challenges when using AHSS for energy absorption by folding is to secure robust behavior. Progressive folding gets harder to achieve in axial crushing as the material strength increases and the thickness is reduced. To increase the robustness, an effective pattern of triggers or change of the global geometry can be introduced.

\section{F. Challenges in forming AHSS}

Forming of AHSS is not a radical change from forming conventional HSS. The major acquisition of new knowledge and experience needed for forming higher strength steels in general increased gradually over the years as ever-increasing strengths became available in the HSLA grades. Now new demands for improved crash performance and reduced mass and cost, have spawned a new group of steels that improve on 
the current conventional base of HSS. The improved capabilities the AHSS bring to the automotive industry do not bring new forming problems but certainly accentuate problems already existing with the application of any higher strength steel. These concerns include higher loads on presses and tools, greater energy requirements, and increased need for springback compensation and control. In addition, AHSS have a greater tendency to wrinkle due to the lack of adequate hold-down and often a reduction in sheet thickness.

Matching exact mechanical properties of the intended steel grade against the critical forming mode in the stamping not only requires an added level of knowledge by steel suppliers and steel users, but also mandates an increased level of communication between them. New emphasis is being placed on determining specific needs of the stamping, highlighting critical forming modes, and identifying essential mechanical properties. The interaction of all inputs to the forming system means the higher loads and energy needs of AHSS also place new requirements on press capacity, tool construction/protection, lubricant capabilities, process design, and maintenance.

Since many applications of AHSS involve load bearing or crash analyses, computerized forming-process development has a special utilization in structural analysis. Previously the part and assembly designs were analyzed for static and dynamic capabilities using CAD stampings with initial sheet thickness and as-received yield strength. Often the tests results from real parts did not agree with the early analyses because real parts were not analyzed. Now virtual parts are generated with pointto-point sheet thickness and strength levels nearly identical to those that will be employed when the physical tooling is constructed. Deficiencies of the virtual parts can be identified and corrected by tool, process, or even part-design before tool construction has even begun.

\section{DISCUSSION}

AHSS forming challenges stem mainly from multi-phase structure and complex manufacturing processes, such as determining the material properties with accuracy requires new testing methods, and batch-to-batch inconsistency is common. Due to their high strength and low formability early fractures are observed in several forming operations, requiring fracture investigation. Larger press capacities are required for forming or blanking and tools wear out quickly. Lubricants, tool materials and coatings require careful selection, while larger springback (leading to dimensional inaccuracy) is an important issue requiring additional development and considerations [4].

\section{A. Inconsistency of mechanical properties}

AHSS are performance-based steel grades. They are named and marketed according to the metallurgical type (DP, TRIP, etc.) and their strength. Steel producers may achieve the required minimum by various chemical and manufacturing processes; several materials can maintain the minimum strength requirement although their chemical compositions may not be constant. Since different mills may have different methods of production, their tensile properties may match while other material parameters such as elongation and weld- ability may vary [5]. Due to the performance based grading, sometimes mills may deliver steels with properties that exceed standard requirements. A stamping company may require an AHSS with a minimum strength of $900 \mathrm{MPa}$. The steel supplier may have a batch that has $1200 \mathrm{MPa}$ strength. Technically, the supplier meets the minimum requirement. However, the formability of a stronger metal will be different [4].

\section{B. Formability}

It is well known that AHSS grades have different failure mechanisms compared to mild steels and HSLA steels. This is mainly caused by local failures which are observed more commonly in forming AHSS, due to multi-phase structure and phase changes during deformation. These local failures do not necessarily correlate with n-value, R-value or total elongation [6].

\section{Lubrication in sheet metal forming}

Lubrication is essential in stamping to avoid metal to metal contact and provide a cooling effect by preventing heat generation and transfer during deformation. Friction and lubrication in sheet metal forming are influenced by various parameters such as material properties, surface finish, temperature, sliding velocity, contact pressure, and lubricant characteristics $[7,8]$. A good understanding of the parameters that affect friction is essential for selecting lubricants and producing good quality sheet metal parts. In sheet metal forming, the magnitude and distribution of friction affect metal flow, part defects and quality, as well as tool wear and production costs; it is one of the process variables that profoundly affect the quality of stamping sheet materials. Using a good lubricant can significantly reduce scrap rate and/or improve the quality of stamping.

Forming AHSS often causes lubricant film break down and galling that increases scrap rates and tool maintenance cost. The increasing use of AHSS in new product designs puts higher demands on tool steels and lubricants used in forming and blanking/punching operations. The use of AHSS has been steadily increasing in vehicle body constructions to enable improved fuel economy and vehicle safety performance. However, the high press loads required for stamping AHSS sheets causes severe chipping and adhesive wear on stamping/blanking die materials [9]. Due to the high strength of AHSS, more forming loads are required. In many cases, forming loads are further increased on purpose, to reduce springback. Due to friction and high cold working, temperatures of tools are higher in forming AHSS. There are studies showing that $1200 \mathrm{C}$ temperatures are not uncommon in production conditions. Higher contact pressures and higher temperatures in the die-sheet interface are both detrimental for lubricants. Lubricant manufacturers recommend High Solids Polymer (HSP) lubricants or synthetic lubricants with Extreme Pressure (EP) additives [10].

\section{Post metal forming operations}

Most of the lubricants are applied on sheet metals before press forming. Lubricants also affect post-metal forming operations such as welding, adhesive bonding, and painting. In 
addition to their good lubricity, lubricants must be easily removable from the formed panels, because the stamped part has to be completely oil-free for painting. Therefore, in selection/evaluation of stamping lubricants, it is necessary to consider advantages and disadvantages of lubricants not only for deep drawing, but also for assembly and painting operations [11].

\section{E. Work hardening and springback}

The work-hardening and springback characteristics of AHSS can require stamping operations to boost press tonnage and increase ram dwell time. The resulting increase in friction and associated heat can break down stamping lubricants, deplete their boundary protection and render them ineffective. In these situations, stampers opt for lubricants with extremepressure (EP) additives such as chlorine, sulphur and phosphorous. Activated by heat, these additives react with metal to form metallic "salts" with low shear strength. These salts provide an additional yet temporary coating to protect the tools and work piece. As the tool and work piece temperatures increase during deformation, lubricants with EP additive become thinner (low viscosity), may burn. On the other hand, the lubricants with extreme temperature (ET) additives become thicker (high viscosity). Lubricants with ET additives stick to the hot work piece and create a friction-reducing film barrier between the tool and the work piece [12].

Dimensional control is extremely important when stamping automotive parts. Newer steels exhibit specific stress-strain curves, resulting in unique springback levels and behaviors. Springback is the tendency for a material to return to its preformed position and has negative consequences for part dimensions. In order for parts to be manufactured in large volumes, each part must be reproducible hit after hit. Researchers must look at how to compensate for springback by examining all the variables in the manufacturing process including tooling, part shape and the machinery itself to ensure volume production repeatability. AHSS research has resulted in the development of new steels, like DP 980 and DP 1180 grades. As new steels with differing stress-strain curves enter the manufacturing pipeline, tooling manufacturers need the data to plug into die-design calculations [13].

\section{CONCLUSION}

The increasing demand for safety in cars necessitates higher strength material to be used in critical safety elements in the car body. A solution to meet these objectives is to use AHSS in the car body. A higher strength work material leads to an increased strength of the formed part and less material may be needed to achieve the desired detail strength [14]. Newly developed grades of advanced high-strength steel (AHSS) significantly outperform competing materials for current and future automotive applications. This is a direct result of steel's performance flexibility, as well as its many benefits including low cost, weight reduction capabilities, safety attributes, reduced greenhouse gas emissions and superior recyclability [15]. AHSS is the most competitive material on the market today. With well proven production processes requiring minimal investments, the higher price of AHSS is quickly offset by reduced volumes. One steel grade of AHSS replaces several traditional steel grades. The increased use of AHSS is leading the way in crash safety. Steel is at the core of the green economy. AHSS provide an excellent way to reduce weight and improve performance. Dual phase and martensitic steels show a good combination of strength, formability and weldability. This, together with the cost-effectiveness of cold forming results in very attractive solutions for body-in-white structural parts, as well as safety parts such as door impact beams, bumper systems and seat structures.

\section{REFERENCES}

[1] DOCOL, "DOCOL's advanced high strength steels for the automotive industry”, DOCOL-SSAB Automotive Brochure, 2012

[2] UDDEHOLM-SSAB, “Tooling solutions for advanced high strength steels-selection guidelines”, SSAB Swedish Steel Brochure, 2013

[3] WorldAutoSteels, Evolving AHSS Types,http://www.worldautosteel.org /steel-basics/steel-types/evolving-ahss-types/

[4] M. S. Billur, T. Altan, "Challenges in forming advanced high strength steels”, Proceedings of New Developments in Sheet Metal Forming, pp. 285-304, 2012

[5] K. S. Choi, W. N. Liu, M. A. Khaleel, "Influence of manufacturing processes and microstructures on the performance and manufacturability of advanced high strength steels”, Journal of Engineering Materials and Technology, Vol. 131, No. 4, pp. 041205-041213, 2009

[6] J. Dykeman, D. Hoydick, T. Link, H. Mitsuji, "Material property and formability characterization of various types of high strength dual phase steel", SAE Technical Paper 2009-01-0794, 2009

[7] H. Kim, H. Palaniswamy, T. Altan, "Investigation of tribological conditions in forming uncoated and galvanized advanced/ultra high strength steels”, CPF, 2, 3/06/01, 2006

[8] N. Bay, A. Azushima, P. Groche, I. Ishibashi, M. Merklein, M. Morishita, T. Nakamura, S. Scmid, M. Yoshida, "Environmentally benign tribo-systems for metal forming”, CIRP Annals-Manufacturing Technology, Vol. 59, No. 2, pp. 760-780, 2010

[9] C. Wang, J. Chen, Z. C. Xia, F. Ren, "Die wear prediction by defining three-stage coefficient $\mathrm{K}$ for AHSS sheet metal forming process”, The International Journal of Advanced Manufacturing Technology, Vol. 69, No. 1-4, pp. 797-803, 2013

[10] H. Kim, T. Altan, Q. Yan, "Evaluation of stamping lubricants in forming advanced high strength steels (AHSS) using deep drawing and ironing tests”, Journal of Materials Processing Technology , Vol. 209, No. 8, pp. 4122-4133, 2009

[11] T. Altan, E. Tekkaya, Sheet Metal Forming: Fundamentals, Volume I, ASM International, 2012

[12] IRMCO, “Lubricant is lubricant”, IRMCO brochure 2012 http://www.irmco.com/lib/Media/irmco_2012_brochure.pdf

[13] L. Kren, "Hurdles to Stamping Giga Pascal Strength Steels AHSS, Metalform”, 2011 http://www.metalformingfacts.com/hurdles-stampinggigapascal-strength-steels.html

[14] H. Kim, Advanced High Strength Steels (AHSS): Evaluation of lubricants, tool materials and coatings for reducing galling, LAP Lambert Academic Publishing, 2009

[15] STEELWORKS, "Steel is the Solution to Achieve 54.5 MPG by 2025", http://www.steel.org/en/Autosteel_org/Web\%20Root/Research/Growth \%20of\%20AHSS.aspx 